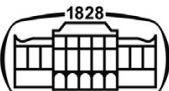

AKADÉMIAI KIADÓ

UNIVERSITY of DEBRECEN

\section{International Review of Applied Sciences and Engineering}

12 (2021) 2, 176-182

DOI:

10.1556/1848.2021.00223

(c) 2021 The Author(s)

\section{ORIGINAL RESEARCH} PAPER

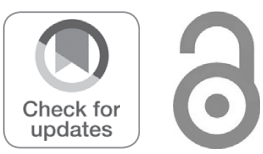

\title{
Effect on the properties of fresh and hardened concrete made using fly ash geopolymer sand
}

\author{
G. Lizia Thankam* ${ }^{\oplus}$, T.R. Neelakantan $\odot$ and \\ S. Christopher Gnanaraj
}

Department of Civil Engineering, Kalasalingam Academy of Research and Education, Krishnankoil 626126, India

Received: December 12, 2020 • Accepted: January 28, 2021

Published online: March 22, 2021

\section{ABSTRACT}

Fly ash-based geopolymer fine aggregate is a potential replacement material for the natural river sand as it has similar physicochemical properties. This paper reports the experimental investigation of a study conducted using this fine aggregate in concrete with a focus on the properties of fresh and hardened concrete. The geopolymer fine aggregate was developed by air curing process and oven curing method. The oven curing method yielded relatively better mechanical properties in concrete specimens. The oven curing results in better behavior at later age also. Laboratory tests were conducted to ascertain the fresh concrete density, slump value, hardened concrete density, compressive strength, tensile strength, and flexural strength of the concrete specimens. The microstructure of the concrete specimens was analyzed using scanning electron microscope which indicated the agglomeration of the fly ash particles with few voids demonstrating the higher water adsorption capacity of the same. The unreacted particles noted in the microstructure later tend to merge with the lime obtained from the hydration of cement so as to develop improved later age mechanical strength. The results on mechanical properties of the concrete indicate much similar results to that of the concrete developed with the normal river sand, which confirms that the geopolymer sand is an ideal replacement choice for natural river sand.

\section{KEYWORDS}

geopolymer sand, SEM, compressive strength, tensile strength, flexural strength, river sand, fine aggregate

\section{INTRODUCTION}

The ever-growing construction industry suffers due to paucity of the natural fine aggregate, the river sand. Extensive utilization of river sand [1] is restricted in many countries as it caused deepening of the riverbed depth [2], increased salinity in the ground water and the reduction in the ground water table [3]. Hence, researchers are trying to find alternate fine aggregate materials. There are limited findings on replacing the fine aggregate completely $[4,5]$. However, researchers continue to explore as fly ash has material and pozzolanic properties required for construction [6-11]. Fly ash from power plants contain traces of $\mathrm{Ca}, \mathrm{Mg}, \mathrm{Na}$ and $\mathrm{K}$ that makes it unfit for the agricultural purpose and further makes it harder to dispose as well as reuse in any other industry. Further, fly ash also degrades the fertility of the soil $[12,13]$. About 450 million tons of fly ash is generated worldwide annually [14] and out of which only $25 \%$ is used by various industries at present. The cost of disposal of fly ash and cost of concrete production are reduced by using it in the construction industry [15].

Though many studied replacement of fine aggregate with fly ash, only the partial replacement with fly ash is noted to develop maximum mechanical strength for the hardened concrete [16]. Geopolymerization, an irreplaceable technique, is already used in the construction industry by replacing the ordinary Portland cement with geopolymers for developing mortars as well as concrete[17, 18]. Geopolymerization of the fly ash is an 
Table 1. Comparison of the F-GFA material properties with NRS

\begin{tabular}{lccc}
\hline Parameter & AD-F-GFA & OD-F-GFA & NRS (natural river sand) \\
\hline Water absorption (\%) & 7.6 & 7.02 & 0.9 \\
$\mathrm{C}_{\mathrm{u}}$ (co-efficient of uniformity) & 3.96 & 3.98 & 1.59 \\
$\mathrm{C}_{\mathrm{c}}$ (Co-efficient of curvature) & 1.08 & 1.2 & 0.82 \\
Compressive strength of mortar $\left(\mathrm{N} / \mathrm{mm}^{2}\right)$ & 17.6 & 19.9 & 23.5 \\
$\mathrm{pH}$ & 10 & 10 & 8 \\
\hline
\end{tabular}

alternate solution to replace the fine aggregate entirely to enhance the concrete properties, which is termed as fly ash polymerized sand (FAPS) [19]. The FAPS is noted to be within the zonal limits and IS Standards [20] imparting compressive strength which is much similar to that of the river sand specimen. Further, the synthesis process was refined, which also yielded the similar results developing $93 \%$ of the mechanical strength similar to that of the specimens of NRS (Natural River Sand) at 28 days of curing $[21,22]$. In another study [23], two types of FA (Fly ash) were developed with class F (High carbon content) geopolymer fine aggregate (F-GFA) and class C (Low carbon content) geopolymer fine aggregate (C-GFA), which were synthesized in a much simpler process compared with the previous studies $[19,21,22]$ and then compared with that of the natural river sand. Both C-GFA and F-GFA were noted to have adequate material properties among which C-GFA specimens attained higher compressive strength than the F-GFA specimens.

In this experimental investigation, fly ash based geopolymerized fine aggregate (F-GFA) is synthesized in a much simpler method and a detailed study is carried out on fresh concrete properties (workability) as well as the mechanical properties (compressive strength, flexural strength, split tensile strength) of hardened concrete.

\section{MATERIALS AND TEST PROCEDURES}

F-GFA is used as fine aggregate throughout this study for which, initially, fly ash is dry mixed with the alkaline solution (sodium hydroxide pellets \& sodium silicate) followed by hand mixing the dry mix for about 10 minutes, which is then developed as geopolymerized fine aggregate (GFA) by both oven-drying method (OD-F-GFA) and airdrying method (AD-F-GFA). Thus, the optimized F-GFA were noted to showcase maximum compressive strength at $10 \mathrm{M}$ of the alkaline solution with the solid/solution ratio of $2.8: 1$ and $\mathrm{Na}_{2} \mathrm{SiO}_{3} / \mathrm{NaOH}$ ratio of 1:2. Upon trial-and-error method, the curing temperature is optimized as $120^{\circ} \mathrm{C}$ for a duration of 60 minutes in OD-F-GFA whereas in AD-FGFA, maximum compressive strength is obtained at 7 days of air curing at $30 \pm 3{ }^{\circ} \mathrm{C}$. After the stipulated period the much coarser particles are removed by hand picking and then the F-GFA is ready to be used in concreting. Both the AD-F-GFA and OD-F-GFA were noted to be categorized under zone I as per IS 383:2016 [24] with the following properties (Table 1) conforming to ASTM C128-15 [25] and IS 2386 [26].

In order to corroborate the findings, a detailed study is conducted on the fresh concrete properties (workability) and mechanical properties (compressive strength, tensile strength and split tensile strength) of hardened concrete. The microstructure of the NRS, FA and F-GFA were analyzed for surface morphology with Scanning Electron Microscope EVO 18 (CARL ZEISS). The micrographs represented the agglomeration of the fly ash particles into GFA [19] after the polymerization process as presented below (Fig. 1). The G-GFA particles showed better agglomeration in the micrograph. Both ordinary Portland cement of 43 grade and natural river sand were acquired from the local industrial market of south India (Author's native), which were included in the concrete preparation in this experimental study. Polycarboxylate based CERAPLAST SP is used as water reducing admixture in the concrete developed with F-GFS. The fly ash for the preparation of GFA were procured from the coal power plant at Tutucorin, $8.7642^{\circ} \mathrm{N}, 78.1348^{\circ} \mathrm{E}$ (Tamilnadu, India).

Portable tap water from the laboratory is used in the casting of the concrete specimens. Coarse aggregates with particle size ranging between 10 and $12.5 \mathrm{~mm}$ with a specific gravity of 2.6 is used throughout this experimental study conforming to IS 383:2016. By involving the absolute volume method [27], several trial mixes were developed assuming a target slump of $75-100 \mathrm{~mm}$ and an optimum compressive strength of $25 \mathrm{~N} / \mathrm{mm}^{2}$. The mix proportion adopted in this study were detailed in Table 2. $0.8 \%$ of polycarboxylate based superplasticizer by the total weight of cement is used throughout the study for achieving the desired slump value. Followed by the slump test [28], tests were carried out to study the mechanical properties of the hardened concrete developed with F-GFA. Three replicate cubes of $150 \times 150 \times 150 \mathrm{~mm}$ size were casted for each trial mix to study the compressive strength of the concrete. Tests were conducted for the same on 7 days, 28 days, 56 days, and 90 days of curing. The flexural strength was tested on three replicate beams of size $100 \times 100 \times 500 \mathrm{~mm}$ and tested for the same on 28 days, 56 days and 90 days of curing. Whereas for split tensile strength test, three replicate cylinders of $300 \mathrm{~mm}$ length and $150 \mathrm{~mm}$ of diameter were casted and tested on 28 days, 56 days, and 90 days of curing. All the specimens were then cured by water curing in the laboratory. 

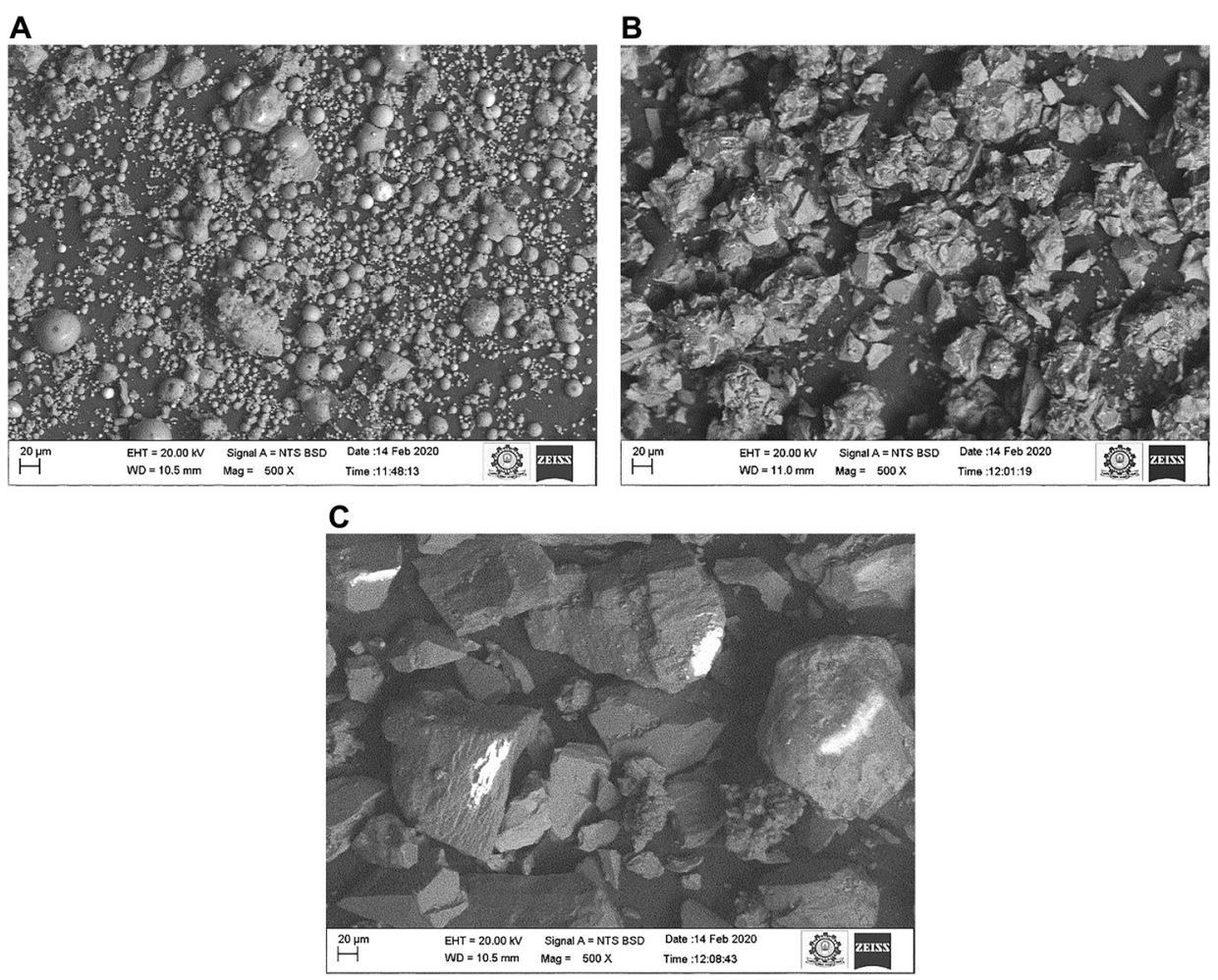

Fig. 1. A SEM image of fly ash. B SEM image of agglomerated fly ash particles. C SEM image of NRS

Table 2. Mix proportioning adopted for the analysis of hardened concrete

\begin{tabular}{lccccccc}
\hline $\begin{array}{l}\text { Type of concrete for } \\
\text { M25 Grade }\end{array}$ & $\begin{array}{c}\text { Water } \\
\left(\mathrm{kg} / \mathrm{m}^{3}\right)\end{array}$ & $\begin{array}{c}\text { Cement } \\
\left(\mathrm{kg} / \mathrm{m}^{3}\right)\end{array}$ & $\begin{array}{c}\text { Fine aggregate } \\
\left(\mathrm{kg} / \mathrm{m}^{3}\right)\end{array}$ & $\begin{array}{c}\text { Coarse aggregate } \\
\left(\mathrm{kg} / \mathrm{m}^{3}\right)\end{array}$ & $\begin{array}{c}\text { Plasticizer } \\
\left(\mathrm{kg} / \mathrm{m}^{3}\right)\end{array}$ & $\begin{array}{c}\text { W/C ratio } \\
\left(\mathrm{kg} / \mathrm{m}^{3}\right)\end{array}$ & $\begin{array}{c}\text { Total Quantity } \\
\left(\mathrm{kg} / \mathrm{m}^{3}\right)\end{array}$ \\
\hline NRS & 197.16 & 328.60 & 683.82 & $1,126.25$ & 2.63 & 0.6 & $2,338.46$ \\
OD-F-GFA & 197.16 & 328.60 & 511.56 & $1,126.25$ & 2.63 & 0.6 & $2,166.20$ \\
AD-F-GFA & 197.16 & 328.60 & 516.78 & $1,126.25$ & 2.63 & 0.6 & $2,171.42$ \\
\hline
\end{tabular}

\section{RESULTS AND DISCUSSIONS}

\subsection{Fresh concrete studies}

The freshly developed concrete mix with OD-F-GFA and AD-F-GFA as fine aggregate were experimentally tested for its fresh concrete parameters such as workability and fresh concrete density in this study. The fine aggregates developed in this study were slightly sprinkled with potable water at the time of usage and then it was incorporated for attaining the concrete mix. The concrete mix is noted to possess good workability and adequate fresh density within the limits.

3.1.1. Workability. In order to achieve better workability in the mix developed with both OD-F-GFA and AD-F-GFA, polycarboxylate based superplasticizers were introduced and a water/cement ratio of 0.63 is practiced throughout the entire study. Though the increased water adsorption ratio of the F-GFA resulted in higher water content for the mix, the slump was noted to fall steadily owing to the well graded nature of both OD-F-GFA and AD-F-GFA. The fresh concrete neither developed bleeding nor segregation due to the cohesive nature of the concrete. The mix appeared to be uniformly graded too.

3.1.2. Fresh concrete density. The density of the fresh concrete (Fig. 2) was noted to be 2,540.28, 2,298.31 and $2,130.46 \mathrm{~kg} / \mathrm{m}^{3}$ for the concrete developed with NRS, OD-FGFA and AD-F-GFA, respectively, indicating the presence of a minimal voids upon the usage of F-GFA as fine aggregate in the concrete. Though the fresh density of FGFA concrete is approximately $10 \%$ lesser than that of the NRS concrete, the well grading of the F-GFA caused better flowability and workability for the F-GFA concrete in par with the NRS concrete.

\subsection{Hardened concrete studies}

In order to ascertain the hardened properties of the concrete developed with OD-F-GFA and AD-F-GFA as fine aggregate the compressive strength, tensile strength and flexural strength of the specimens were experimentally analyzed with the Universal Testing Machine (Fig. 3) and the results were subsequently compared with those of the concrete developed 


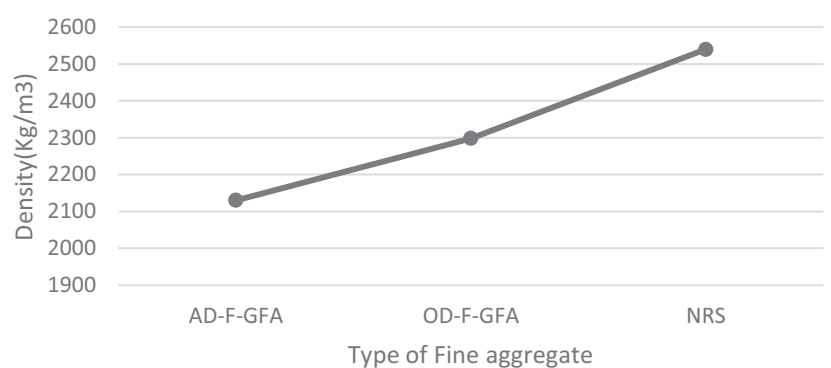

Fig. 2. Fresh concrete density of F-GFA samples compared with NRS

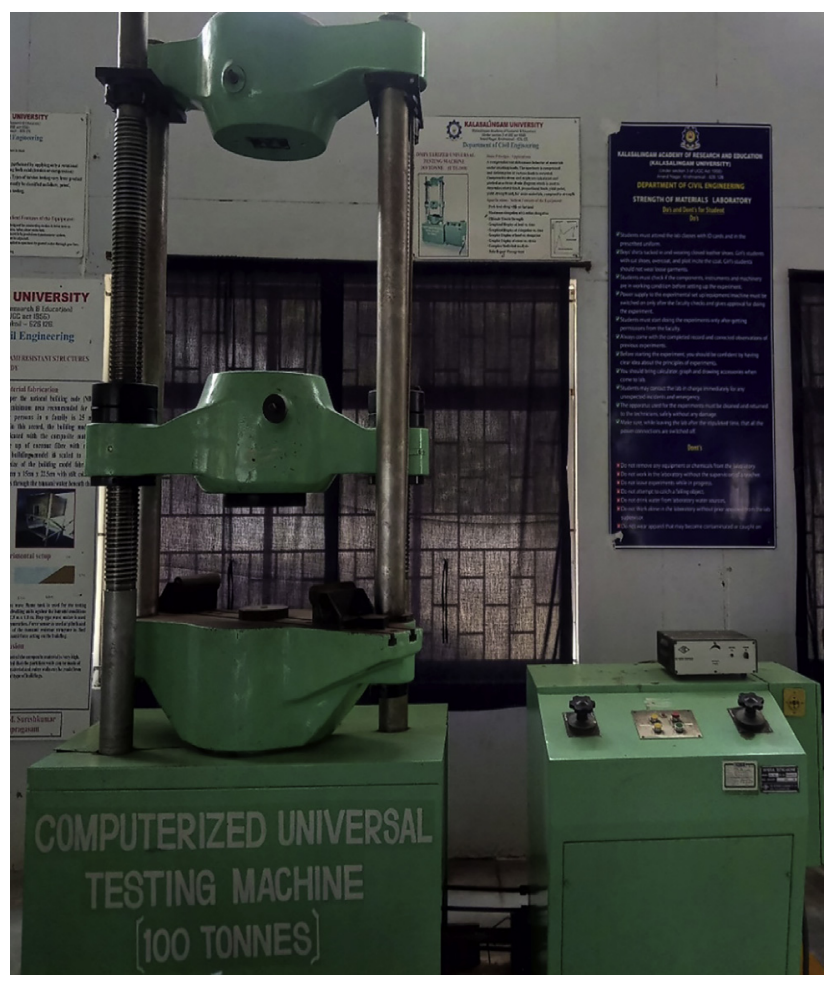

Fig. 3. Universal testing machine

with the NRS (control mix). The dry density of the casted samples was also studied along with the mechanical properties.

3.2.1. Dry density. The dry density of the specimens was also obtained so as to co-relate the observations with the same (Fig. 4). The dry density of OD-F-GFA and AD-FGFA concrete specimens were noted to achieve 81 and $79 \%$ of the dry density of NRS at 28 days, respectively. The ODF-GFA and AD-F-GFA concrete specimens also indicated a rise of 7.34 and $6 \%$, respectively, in the dry density at 90 days of curing when compared with that of the 28 days of curing. Whereas the NRS showcased a decline of $2 \%$ in the dry density at 90 days when compared with that of the 28 days of cured concrete specimens. The leaching of the silica and alumina particles [21] in fly ash developed by the geopolymerization technique attributes the rise in the dry density of the AD-F-GFA and OD-F-GFA at later age (90 days) in the concrete specimens.

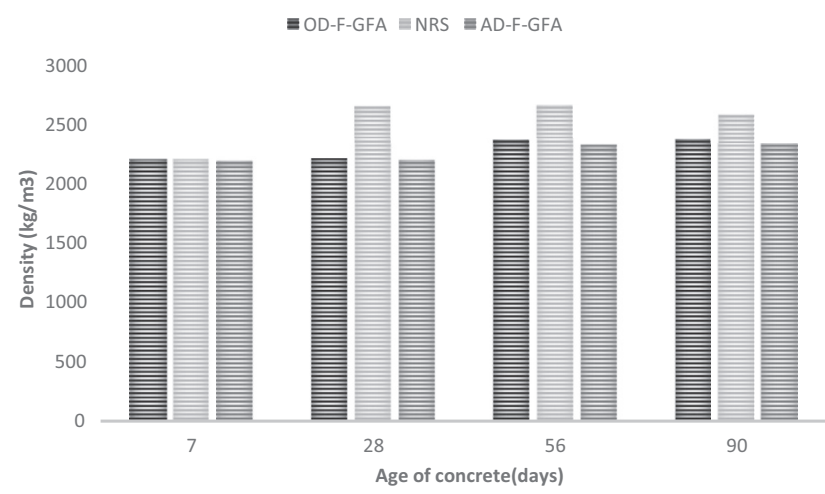

Fig. 4. Variation in dry density of hardened concrete developed with F-GFA compared with NRS

3.2.2. Compressive strength. The compressive strength of the AD-F-GFA and OD-F-GFA concrete specimens were experimentally tested [29] in order to ascertain the mechanical behavior of the same at 7 days, 28 days, 56 days and 90 days (Fig. 5). The OD-F-GFA and AD-F-GFA concrete specimens developed 75 and $69 \%$ of compressive strength to that of the NRS. Whereas at 90 days of curing, OD-F-GFA and AD-F-GFA concrete specimens showed up 94 and $90 \%$ of compressive strength to that of the NRS owing to the later age strength development of the fly ash along with the alkali activation by $\mathrm{Si}$ and $\mathrm{Al}$ components due to geopolymerization process $[30,31]$. However, the compressive strength developed in OD-F-GFA concrete specimens were noted to be higher than that of the AD-F-GFA concrete specimens since the increased heat from oven curing accelerates the rate of strength gain up to an extent [32].

3.2.3. Tensile strength. The tensile strength of the specimens developed with AD-F-GFA and OD-F-GFA as fine aggregate were experimentally analyzed [33] to ascertain the results consequently comparing the same with that of the NRS (Fig. 6). The 28 days tensile strength of AD-F-GFA and OD-F-GFA were 62 and 77\%, respectively, to that of the NRS.

The specimens examined for tensile strength at 56 days of curing developed 90 and $94 \%$ of the tensile strength for AD-FGFA and OD-F-GFA, respectively, when compared to that of

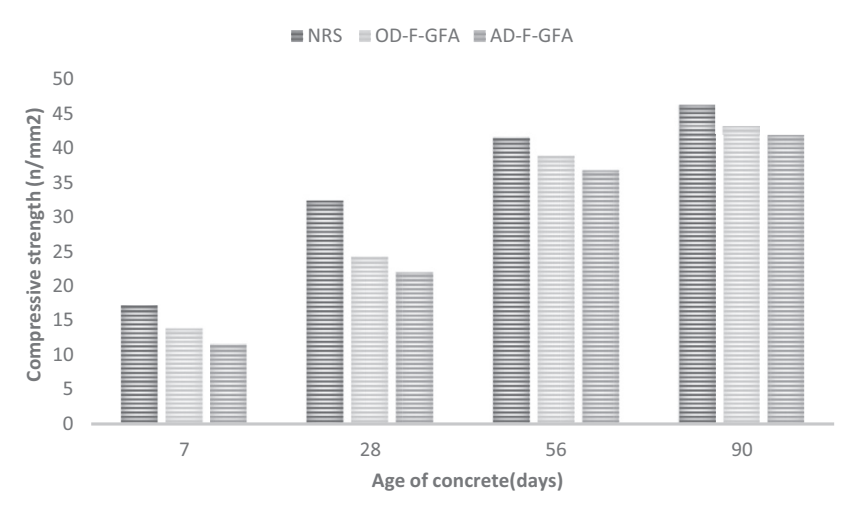

Fig. 5. Compressive strength test results of the F-GFA specimens compared with NRS 


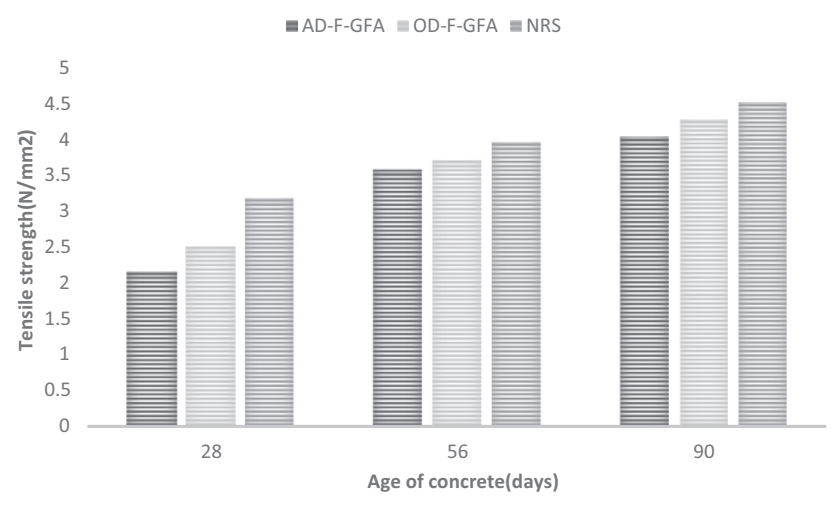

Fig. 6. Tensile strength test results of the specimens developed with F-GFA compared with NRS

the NRS [34]. The later age strength developed a significant rise in the tensile strength up to 89 and $95 \%$ for AD-F-GFA and OD-F-GFA, respectively, in par to the NRS due to the alkali activation process inside the concrete developed with geopolymer sand (F-GFA). Though the strength attainment of the specimens at 28 days of curing was noted to be moderate, it rapidly improved at the later age of 56 days and 90 days owing to the unreacted particles, which later on merged with the phase due to the geopolymerization process.

3.2.4. Flexural Strength. The flexural strength of the specimens in this experimental study were examined experimentally at 28 days, 56 days and 90 days (Fig. 7). Much similar patterns to the results of the tensile strength were noted for the flexural strength of the concrete specimens developed with AD-F-GFA and OD-F-GFA as the fine aggregate. 79 and $60 \%$ of strength attainment at 28 days, 96 and $90 \%$ of strength attainment at 56 days and 94 and $91 \%$ of strength attainment is recorded at 90 days for OD-F-GFA and AD-F-GFA specimens, respectively. These results clearly indicate that the later age (56 days and 90 days) strength attainment is higher in the concrete specimens developed with OD-F-GFA and AD-F-GFA as fine aggregate due to the later age strength attainment of fly ash [35-37] as well as the reaction of the unreacted particles in later age by

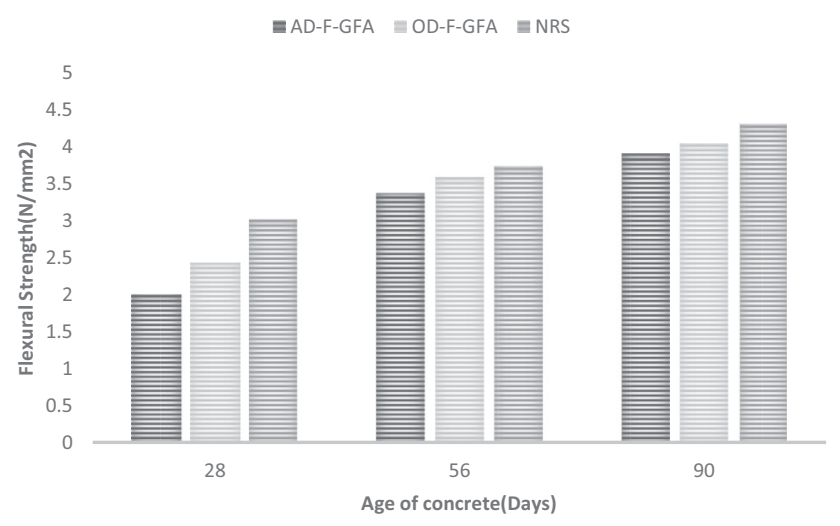

Fig. 7. Flexural Strength test results of specimens obtained with FGFA compared with NRS the stimulation of the alkali activators in the GFA. Thus the GFA showcased good fresh and hardened properties throughout this study indicating the feasibility of the same [38] in concrete Industry.

\section{CONCLUSION}

Based on observations, the following conclusions were drawn:

1. The F-GFA developed with a solid:solution ratio of 2.8:1 involving an alkaline solution of $10 \mathrm{M}$ exhibiting similar physicochemical properties of the NRS.

2. The OD-F-GFA turned out to be the ideal one with better mechanical properties and workability than the AD-FGFA due to the accelerated geopolymerization process through oven curing thereby mitigating the water absorption ratio.

3. The micrographs from scanning electron microscope clearly substantiate the agglomeration of the fly ash particles. A few unreacted particles along with some voids in between were also noted.

4. The workability and the fresh concrete density of F-GFA concrete were $90 \%$ closer to that of the NRS concrete.

5. The concrete specimens of OD-F-GFA achieved a maximum of $81 \%$ of dry density compared to that of the NRS concrete specimens at 28 days which is higher than the AD-F-GFA.

6. At 90 days of water curing under the laboratory conditions (room temperature $30^{\circ} \pm 3{ }^{\circ} \mathrm{C}$ ), the concrete specimens of OD-F-GFA developed $94 \%$ and the concrete specimens of AD-F-GFA developed $90 \%$ of compressive strength compared to that of the NRS concrete. This may be attributed to the accelerated alkali activation process by $\mathrm{Si}$ and $\mathrm{Al}$ elements through geopolymerization process.

7. The tensile strength and the flexural strength were higher for OD-F-GFA concrete by 95 and 94\%, respectively, at 90 days when compared with the NRS concrete, which are also higher than the results obtained for the AD-FGFA concrete. The reason can be the unreacted particles that developed the pores and elevated the water absorption ratio.

8. Though the mix developed a w/c ratio of 0.6 , the higher water absorption nature of the G-GFA controlled the segregation and bleeding too with no excess water during the concreting of the mix paving way for a denser concrete with improved mechanical properties.

9. Altogether, the results show F-GFA has the potential to be included in concrete. The following points may be studied further for better understanding.

a. The implementation of the industrialization process for the large-scale manufacturing of the F-GFA

b. Thermal behavior of the F-GFA concrete and the variation of the same under different climatic conditions 
c. Future research to minimize the cost by identifying much simpler procedure for the synthesis of the fly ash based geopolymer sand.

d. Research on minimizing the w/c ratio to be studied

Data Availability: All data, models, and code generated or used during the study appear in the submitted article.

Conflict of interest: There is no conflict of interest.

\section{ACKNOWLEDGEMENT}

The authors greatly acknowledge the full-fledged support both financially and technically by the Kalasalingam Academy of Research and Education (KARE), Deemed to be University, India. The entire experimental works were carried out in the concrete technology laboratory of the Civil Engineering Department, KARE.

\section{REFERENCES}

[1] J. Temuujin, A. Van Riessen, and K. J. D. MacKenzie, "Preparation and characterisation of fly ash based geopolymer mortars," Constr. Build. Mater., vol. 24, pp. 1906-10, 2010.

[2] R. S. Patgaonkar, D. Ilangovan, P. Vethamony, M. T. Babu, S. Jayakumar, and M. D. Rajagopal, "Stability of a sand spit due to dredging in an adjacent creek," Ocean Eng., vol. 34, nos 3-4, pp. 638-43, 2007.

[3] J. T. Gourley, "Geopolymers; opportunities for environmentally friendly construction," in Materials 2003 Conference: Adaptive Materials for a Modern Society, Sydney, Institute of Materials Engineering Australia, 2003 October.

[4] A. H. Mir, "Replacement of natural sand with efficient alternatives: Recent advances in concrete Technology," J. Eng. Res. Appl., vol. 5, no. 3, ( Part-3), pp. 51-8, March 2015. Available at: www. ijera.com.

[5] B. V. V. Reddy, Suitability of Manufactured Sand (M-Sand) as Fine Aggregate in Mortars and Concrete, 2012.

[6] M. Ahmaruzzaman, "A review on the utilization of fly ash," Prog. Energ. Combust. Sci., vol. 36, no. 3, pp. 327-63, 2010.

[7] N. Bouzoubaa, M. H. Zhang, and V. M. Malhotra, "Mechanical properties and durability of concrete made with high-volume fly ash blended cements using a coarse fly ash," Cem. Concr. Res., vol. 31, no. 10, 2001.

[8] A. L. A. Fraay, J. M. Bijen, and Y. M. De Haan, "The reaction of fly ash in concrete a critical examination," Cem. Concr. Res., vol. 19, no. 2, pp. 235-46, 1989.

[9] T. Hemalatha and A. Ramaswamy, "A review on fly ash characteristics-Towards promoting high volume utilization in developing sustainable concrete," J. Clean. Prod., vol. 147, pp. 546-59, 2017.

[10] P. K. Mehta, "High-performance, high-volume fly ash concrete for sustainable development," in Proceedings of the International Workshop on Sustainable Development and Concrete Technology, Ames, IA, US, Iowa State University, 2004.
[11] X. Y. Zhuang, L. Chen, S. Komarneni, et al., "Fly ash-based geopolymer: Clean production, properties and applications," J. Clean. Prod., vol. 125, pp. 253-67, 2016.

[12] D. C. Adriano, A. L. Page, A. A. Elseewi, A. C. Chang, and I. Straughan, "Utilization and disposal of fly ash and other coal residues in terrestrial ecosystems: A review," J. Environ. Qual., vol. 9, no. 3, pp. 333-44, 1980.

[13] I. B. Topcu, "Physical and mechanical properties of concretes produced with waste concrete," Cem. Concr. Res., vol. 27, no. 12, 1997.

[14] H. Zhao, W. Sun, X. Wu, and B. Gao, "The properties of the self-compacting concrete with fly ash and ground granulated blast furnace slag mineral admixtures," J. Clean. Prod., vol. 95, 2015.

[15] K. H. Mo, T. C. Ling, U. J. Alengaram, S. P. Yap, and C. W. Yuen, "Overview of supplementary cementitious materials usage in lightweight aggregate concrete," Constr. Build. Mater., vol. 139, pp. 403-18, 2017.

[16] R. Siddique, "Effect of fine aggregate replacement with class F fly ash on the mechanical properties of concrete," Cem. Concr. Res., vol. 33, pp. 539-47, 2003.

[17] A. Palomo, A. Macias, M. T. Blanco, and F. Puertas, "Physical, chemical and mechanical characterization of geopolymers," in Proceedings of the 9th International Congress on the Chemistry of Cement, New Delhi, India, vol. 5, 1992, pp. 505-11.

[18] D. Hardjito and B. VijayaRangan, Development and Properties of Low-Calcium Fly Ash-Based Geopolymer Concrete, 2005.

[19] S. M. Rao and I. P. Acharya, "Synthesis and characterization of fly ash geopolymer sand," J. Mater. Civil Eng., vol. 26, no. 5, pp. 912-7, 2014.

[20] IS 2386:1963, Methods of Test for Aggregates for Concrete, Bureau of Indian Standards.

[21] U. S. Agrawal, S. P. Wanjari, and D. N. Naresh, "Characteristic study of geopolymer fly ash sand as a replacement to natural river sand," Constr. Build. Mater., vol. 150, pp. 681-8, 2017.

[22] A. K. Sharma and K. B. Anand, "Comparative study on synthesis and properties of geopolymer fine aggregate from fly ashes," Constr. Build. Mater., vol. 198, pp. 359-67, 2019.

[23] S. P. Wanjari, U. S. Agrawal, and D. N. Naresh, "Geopolymer sand as a replacement to natural sand in concrete," in IOP Conference Series: Materials Science and Engineering, vol. 431, no. 9, IOP Publishing, 2018, p. 092011.

[24] Bureau of Indian Standard (BIS), Specification for Coarse and Fine Aggregate from Natural Sources for Concrete, IS 383:2016 New Delhi, India, 2016.

[25] ASTM C128-15, Standard Test Method for Relative Density (Specific Gravity) and Absorption of Fine Aggregate, West Conshohocken, PA, ASTM 2015 International.

[26] Bureau of Indian Standards (BIS), Method of Test for Aggregate for Concrete Particle Size and Shape, IS 2386 (Part-I) New Delhi, India, 1963.

[27] M. L. Gambhir, Concrete Technology, Tata McGraw-Hill Education Publication, 2013, p. 314.

[28] ASTM C143M-15a, Standard Test Method for Slump of HydraulicCement Concrete, West Conshohocken, PA, ASTM International, 2015.

[29] Bureau of Indian Standards, Method of Testing and Sampling of Concrete, IS:1199-1959 1959 New Delhi India, 1959.

[30] G. Sung, Y. Bok, K. Taek, and Y. Soo, "The mechanical properties of fly ash based geopolymer concrete with alkaline activators," Constr. Build. Mater., vol. 47, no. 2013, pp. 409-18, 2015. 
[31] K. D. Weerdt, M. B. Haha, G. L. Saout, K. O. Kjellsen, H. Justnes, and B. Lothenbach, "Hydration mechanisms of ternary Portland cements containing limestone powder and fly ash," Cem. Concr. Res., vol. 41, no. 3, pp. 279-91, 2011.

[32] V. Supraja and M. Kanta Rao, "Experimental study on geo-polymer concrete incorporating GGBS," Int. J. Electron. Commun. Soft Comput. Sci. Eng. (IJECSCSE), vol. 2, no. 2, p. 11, 2012.

[33] ASTM C496/C496M-17, Standard Test Method for Splitting Tensile Strength of Cylindrical Concrete Specimens, West Conshohocken, PA, ASTM International, 2017.

[34] A. Oner, S. Akyuz, and R. Yildiz, "An experimental study on strength development of concrete containing fly ash and optimum usage of fly ash in concrete," Cem. Concr. Res., vol. 35, pp. 1165-71, 2005.
[35] R. Siddique, "Performance characteristics of high-volume class F fly ash concrete," Cem. Concr. Res., pp. 487-93, 2004.

[36] G. Carette and V. M. Malhotra, "Early-age strength development of concrete incorporating fly ash and condensed silica fume," Special Publication, vol. 79, pp. 765-84, 1983.

[37] X. Zhuang, Y. Liang, and V. M. Malhotra, "Durability of concrete incorporating high-volume of low-calcium (ASTM class F) fly ash," Cem. Concr. Compos., vol. 12, pp. 271-7, 1990.

[38] G. Thankam Lizia, T. R. Neelakantan, and S. Gnanaraj Christopher, "Potential of fly ash polymerized sand as an alternative for river sand in concrete-a state of the art report," in IOP Conference Series: Materials Science and Engineering, vol. 1, IOP Publishing, 2020, p. 012039. 